\title{
Normativa para la interacción entre Sociedad Chilena de Enfermedades Respiratorias e Industria Proveedora de Salud ${ }^{\wedge}$
}

\author{
LAURA MENDOZA I.* y MAURICIO RIQUELME O.**
}

\section{Regulations for interaction between Chilean Society of Respiratory Diseases and Health Provider Industry}

La relación de nuestra Sociedad Científica con la Industria Proveedora de Salud es necesaria para lograr apoyo en diversos objetivos de nuestra sociedad: educación continua tanto médica como de pacientes y comunidad, apoyo a investigación, apoyo para difusión, etc.

Como sociedad científica debemos facilitar que dicha relación funcione dentro de marcos regulatorios claros que disminuyan posibles conflictos de intereses entre ambas partes.

El Directorio de la Sociedad Chilena de Enfermedades Respiratorias 2020 -2021 aprobó en reunión del viernes 19 de junio de 2020 la siguiente normativa de interacción entre Sociedad Chilena de Enfermedades Respiratorias e Industria Proveedora de Salud para el funcionamiento de esta interacción dentro de un marco establecido $\mathrm{y}$ conocido por todos nuestros socios.

\section{Normativa aprobada}

1) La Sociedad Chilena de Enfermedades Respiratorias tendrá control del programa académico de los eventos científicos, ya sea a través del comité científico o de las comisiones u otras instancias dentro de nuestra sociedad científica. Los invitados por la industria Proveedora de Salud a asistir a dichos eventos serán acomodados e inscritos por la misma industria.

2) La Sociedad Chilena de Enfermedades Respiratorias resguardará su independencia científi- ca en todas sus instancias y canales de difusión (página web, correos, redes sociales, etc.). Así todo el material educativo/científico debe ser elaborado con independencia de la industria Proveedora de Salud. No obstante, se permite ayuda en gestión y difusión de dicho material por parte de la industria, siempre y cuando no se incluya material promocional.

3) La Sociedad Chilena de Enfermedades Respiratorias aceptará "grants" o auspicios de parte de la Industria Proveedora de Salud destinados a apoyar proyectos de investigación, educación, desarrollo, difusión y otros eventos, siempre y cuando se cumplan las siguientes premisas:

a. Dichos proyectos hayan surgido al interior de las comisiones $y / o$ filiales $u$ otras instancias dentro de nuestra sociedad.

b. El programa propuesto haya sido revisado y aprobado por el Directorio y/o Comité Científico de nuestra sociedad.

c. No incluya promoción de productos por parte de industria proveedora de salud.

4) Los eventos organizados por las filiales y comisiones de la Sociedad Chilena de Enfermedades Respiratorias que reciban apoyo financiero aportado por la Industria Proveedora de Salud deberán ser canalizados a través de nuestra sociedad y no de forma directa con miembros de dichas filiales o comisiones.

^Normativa aprobada en sesión del directorio de la SER, realizada en Santiago el 19 de junio de 2020.

* Presidenta Sociedad Chilena de Enfermedades Respiratorias.

** Secretario Sociedad Chilena de Enfermedades Respiratorias. 
5) Las Industrias Proveedoras de Salud que auspicien las actividades científicas de la Sociedad Chilena de Enfermedades Respiratorias serán explícitamente reconocidas en gesto de agradecimiento resguardando que no habrá promoción de sus productos y que este auspicio no es condicionado.

6) El Directorio de la Sociedad Chilena de Enfermedades Respiratorias y los coordinadores de las comisiones no deberán tener contratos como asesores de la Industria Proveedora de Salud y ningún tipo de contrato con industrias tabacaleras.

7) Todo conferencista en eventos y cursos de la Sociedad Chilena de Enfermedades Respiratorias deberá realizar declaración de conflictos de interés con la industria Proveedora de Salud a los organizadores y luego al público al comienzo de su charla. 